\title{
Isolated by Caste: Neighbourhood-Scale Residential Segregation in Indian Metros
}

\author{
Naveen Bharathi \\ Indian Institute of \\ Management Bangalore
}

naveen.bharathi@iimb.ac.in

\author{
Deepak Malghan \\ Indian Institute of \\ Management Bangalore \\ dmalghan@iimb.ac.in
}

\author{
Andaleeb Rahman \\ Cornell University
}

ar687@cornell.edu

\begin{abstract}
$\underline{\text { ABSTRACT }}$
We present the first ever neighbourhood-scale portrait of caste-based residential segregation in Indian cities. Residential segregation studies in Indian cities have relied on ward-level data. We demonstrate in this paper that wards cannot approximate an urban neighborhood, and that they are heterogeneous. For a typical ward, the neighbourhood-ward dissimilarity index is greater than the wardcity dissimilarity index. Using 2011 enumeration block (EB) level census data for five major cities in India - Bengaluru, Chennai, Delhi, Kolkata, and Mumbai - we show how patterns of caste-based urban residential segregation operate in contemporary India. We also present the first visual snapshot of castebased residential segregation in an Indian city using georeferenced EB level data for Bengaluru. Besides implications for policy, our analysis also points to the need for publicly available, geospatially-linked neighborhood-scale census data that includes data on economic class for a spatial understanding of economic and social stratification within Indian cities.
\end{abstract}




\section{Introduction}

Caste in India is one of the most complex and rigid social structures whose basic characteristics include complex network of hierarchies, segmentation, and segregation (Ghurye 1969). An individual's caste marker is closely correlated with both class and power (Béteille 1965). Spatial segregation and discrimination have been one of the basic aspects of the caste system (A. R. Desai 1994). Many founding fathers of the Indian Constitution including most famously, Ambedkar, advocated greater urban migration for Dalits (previously known as 'untouchables', and administratively referred to as the 'Scheduled Castes') as a solution to escape the most egregious consequences of caste. The structure of caste in the process of urbanization is expected to fuse with class blurring some of the most pernicious consequences of caste-based stratification. Andre Beteille (1997) has argued that in urban India, social status is determined by the markers of class (income, wealth, and education) rather than caste. It has been assumed that that caste does not control the organization of spatial environment of a city as it does in a village (Swallow, 1982). Contemporary Dalit intellectuals continue to believe that, 'caste is losing, and will continue to lose, its strength' in the wake of rapid urbanization India (C. B. Prasad 2010). Historically, many lower caste communities have migrated to cities to 'escape' caste hegemony in the villages. A particularly well-known example is that of Mahars of Maharashtra (hitherto, an 'untouchable' caste group) who migrated to cities like Bombay and Nagpur in large numbers at the beginning of the 20th century (Rao 2009). More recently, the population of Dalits across urban areas saw an increase of 40 percent between the decennial census counts of 2001 and 2011. ${ }^{1}$ In contemporary India, caste continues to have a major impact on various socio-economic outcomes like education, health, labor markets and electoral politics (Borooah 2010; Kothari 1995; Nambissan 2009; Thorat \& Neuman 2012). Rights, access, citizenship and privileges of an individual are often tied to his or her membership of a particular caste (Deshpande 2000, 2001; Thorat, Banerjee, Mishra, \& Rizvi 2015; Thorat \& Neuman 2012).

One of the primary manifestations of the caste system is residential segregation (Ghurye 1969). Even in contemporary rural India, residential areas are divided along caste lines. Castes lower in the hierarchy (and especially Dalits) predominantly live on the outskirts of the village; and inside the village proper, different quarters are strictly segregated along caste lines. Such arrangement also regulates castes' access to public goods such as village well, grazing fields, etc. The social distance and hierarchies of various castes are reflected in the spatial segregation of residential localities in a settlement (Mukherjee 1968). Caste-based residential segregation further contributes to widening of social and cognitive distances between caste groups. Social hierarchies are further reinforced by spatial isolation and separation. Greater the segregation voluntarily or involuntarily - lesser is the likelihood of interaction between communities. Muslims in Indian cities are a classic example of such isolation and ghettoization (Gayer \& Jaffrelot 2012). The possibilities of close relationships on the basis of social equality are greatly reduced. Instead, contacts tend to be formalized, confined principally to the market place or work place (Hazlehurst 1970). Such contacts are usually marginal, and devoid of any sustaining social value. People who work together or who have contacts of a strictly economic character may live in entirely different social and ecological worlds (Gist \& Fava 1970).

There are very few formal quantitative characterization of patterns of urban segregation in India. Given data limitations that we describe here, ethnographic accounts have dominated the literature (for example, Gist 1957; Hazlehurst 1970; Lynch 1967). Census of India reports caste information as three broad aggregate categories - Scheduled Caste (SC), Scheduled Tribe (ST), and Others. In urban areas, population numbers of these three broad aggregate groups were, until 
recently, only reported by the census at the level of ward. Thus the unit of residential segregation analysis, therefore, has been limited in both spatial resolution as well as ethnic resolution (Dupont 2004; Sidhwani 2015; Vithayathil \& Singh 2012). As extant studies have noted, there are serious limitations of using ward-level census data to study caste segregation in a city. The average population in an urban ward can vary from 1500 to 6000 for small statutory towns and municipalities. In larger metropolitan cities, ward size may vary from 30,000 to 200,000 (R. N. Prasad 2006). Hence for studying neighborhood level segregation, a ward is scarcely the most useful spatial unit of analysis. A census enumeration block (or sub-block, that we advocate as a more appropriate neighbourhood proxy in this paper) has around 100-125 households with a population of 650-700 (Socio-Economic and Caste Census 2011). Figures 1 and 2 illustrate the limitations of using ward level data as a proxy for neighbourhood residential segregation. Even without accounting for social groups, these maps show substantive intra-ward variation in distribution of people in Bengaluru. The maps show how the EBs within a ward are heterogeneous even in terms of aggregate population numbers.

A necessary preliminary for any formal analysis of neighbourhood-scale residential segregation is a plausible definition of what constitutes a neighborhood unit. There is no universal definition of a 'neighbourhood unit' in the literature. Urbanists have used diverse approaches to define the scale of an ideal neighborhood. Every individual living in an urban area can perceive the scale of the neighborhood very differently (Chaskin 1994; Lee \& Campbell 1997; Logan \& Collver 1983). Except where unambiguously defined by natural or built boundaries such as roads, lakes, gardens etc., the size and scale of the neighborhood is a matter of individual perception by inhabitants of an area. However, any study of residential segregation is predicated on a welldefined, consistent, and comparable definition of an 'analytic neighbourhood' if not a perceptual neighbourhood. Urban residential segregation studies in the United States have typically used Census tract as the preferred spatial unit of analysis (Iceland \& Weinberg 2002; Massey \& Denton 1987). Census tracts comprise of approximately 4000 people and the boundaries of a census tract have been stable over many decennial censuses to permit historical time-series analysis. Indian ward and census EB boundaries are constantly redrawn making any longitudinal study of urban areas impossible. In the absence of a consistently defined analytic neighborhood unit, segregation studies in India are limited by the spatial resolution of available administrative data. However, such arbitrary choices of spatial scales are not typically congruent with perceived neighbourhood units. 


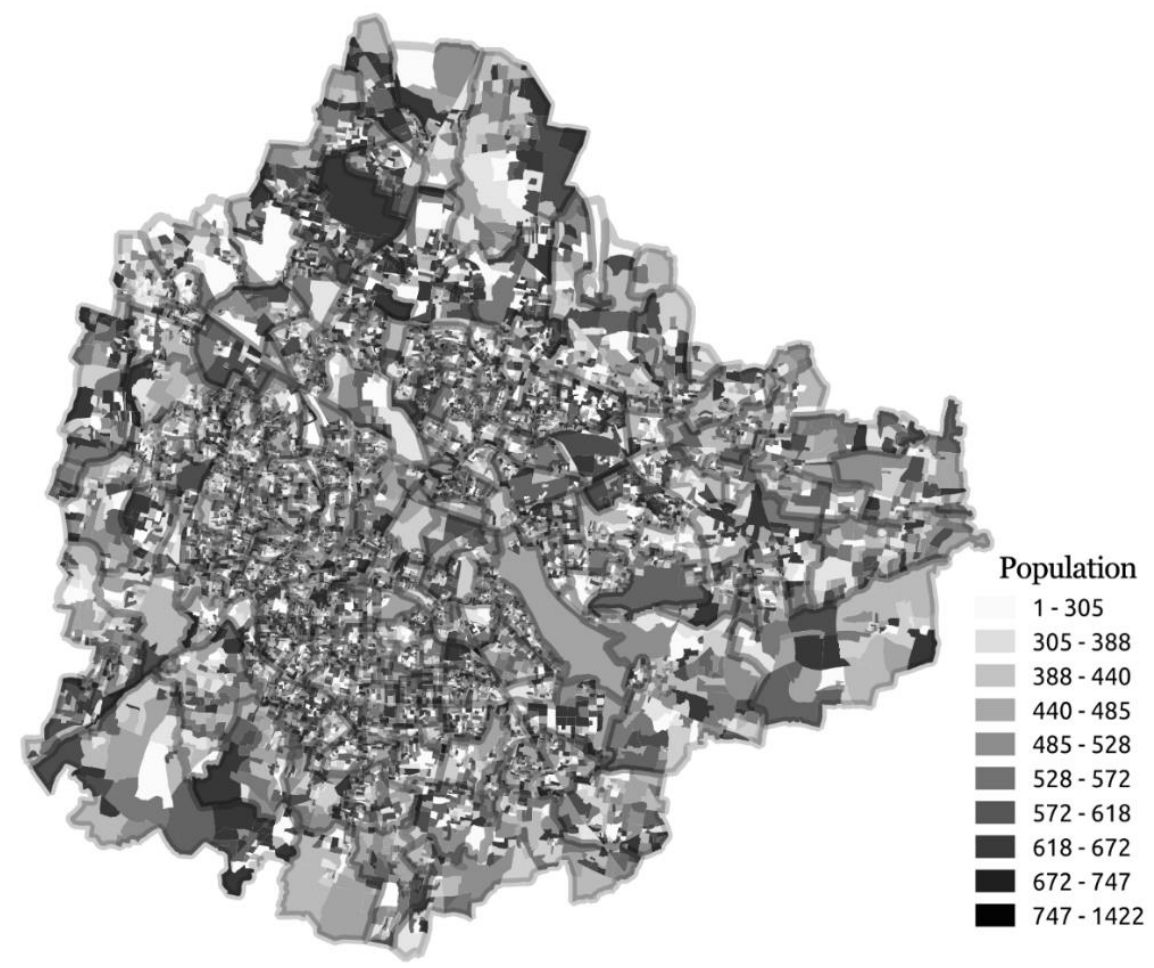

Figure 1: Bengaluru Enumeration Block level Population Map. Uniform ward-level population has been the staple of urban policy analysis in India. This map for Bengaluru shows how there is significant intra-ward variation in population. The population numbers, ward boundaries, and block boundaries are all from Census of India (2011). Also cf. Figure-2 and Figure-3.

Segregation studies on Indian cities have treated ward as a neighborhood. Even if a ward is diverse in terms of caste composition, the communities might be highly segregated within a ward. In Bengaluru for example, upper caste neighborhoods are often abutted by highly dense lower caste settlements. Thus even when spatially proximate, the social distance between these neighborhoods can be very high (Shaw 2012). Clustering can happen even at a micro streel-level, with households from two different castes occupying adjoining streets, or even two different sides of the same street. Hence, the ideal unit of analysis must be still smaller - say a street. Given the compact spatial spread of an urban census enumeration block, we argue that that they represent a good proxy for neighbourhoods. Of the five cities that we study, we are able to visually test this assumption in the case of Bengaluru where we use geo-referenced enumeration block level data. For the four other cities, we use enumeration block data that is not geo-referenced. To the best of our knowledge, this paper is the first ever attempt to use enumeration block (EB) data (released in 2015) to study caste-based residential segregation in India. 


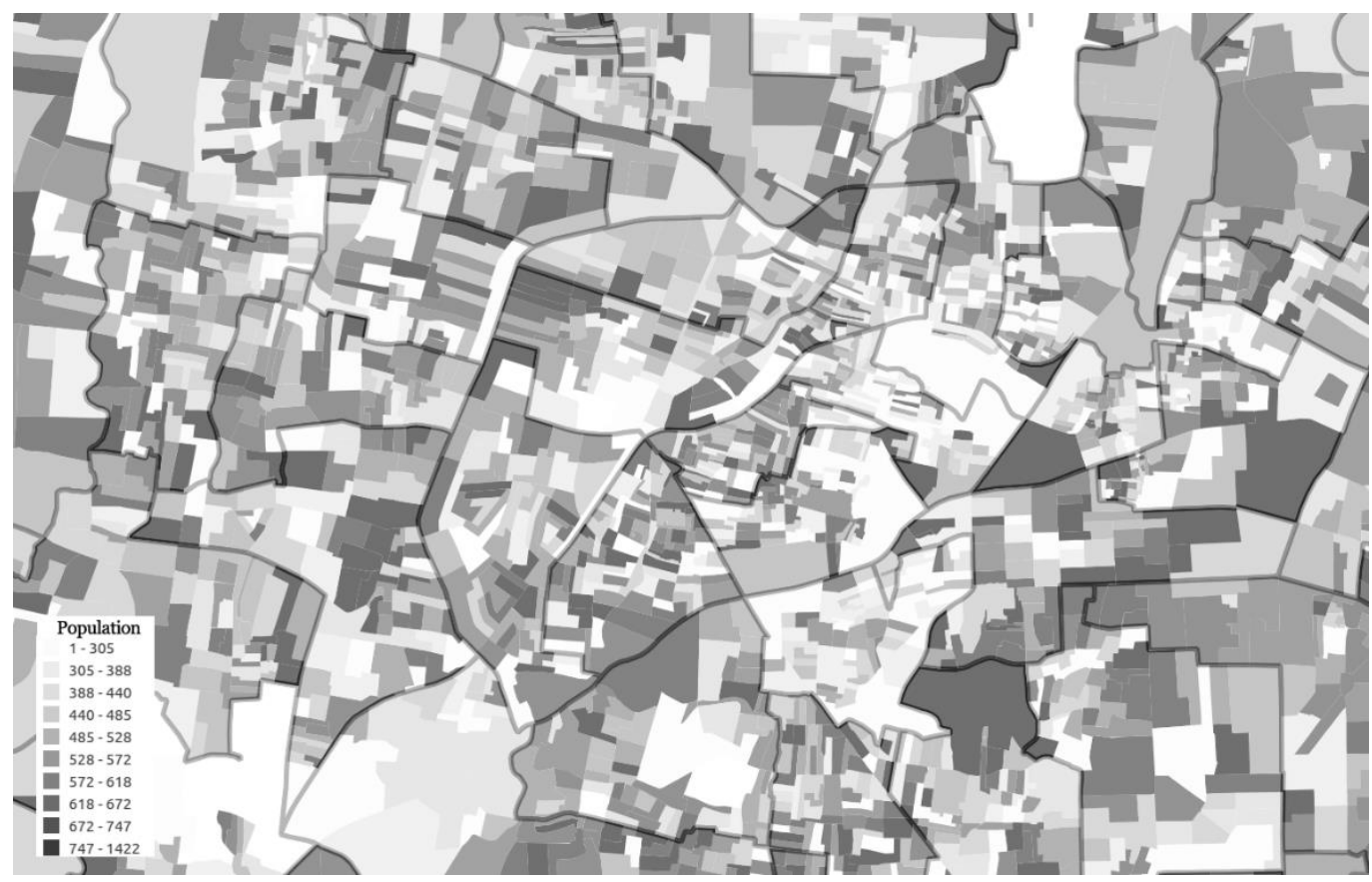

Figure 2:Variation of population within wards in Bengaluru. This figure simply magnifies a particular portion of Figure-1 to better illustrate ward boundaries and thus intra-ward variation in populations.

Using EB data, and comparing it with ward level information, this paper shows why the usage of ward as a unit to study spatial segregation grossly understates the true extent of castebased residential segregation in urban India. The remainder of the paper is organized as follows. The next section provides a brief overview of various attempts to study urban spatial segregation in India. In the following section, we discuss our data and the methodology, and more rigorously defend the census enumeration block as the appropriate spatial unit of analysis for studying residential segregation. Following an analytical discussion of our key results, we present India's first ever visual map of residential segregation using enumeration block map for the city of Bengaluru, before concluding with object lessons for research as well as policy.

\section{Why Study Residential Segregation?}

Residential segregation refers to spatial separation of different social-economic groups in a given geographical area. People can be residentially segregated along various dimensions class, race, language, religion etc., or a combination of these. Data on residential segregation along caste lines when combined with data on levels of urbanization, and rural-urban migration patterns can help empirically test a widely-held normative belief that urbanization reduces caste based spatial segregation.

The patterns and characteristics of residential segregation in US and European settlements have been extensively studied - earliest studies on the subject date back to efforts from the so-called Chicago School (see for example, Burgess 1928; Park, Burgess, McKenzie, \& Wirth 1925). The segregation of African Americans and other ethnic minority groups in US cities have been a subject of continuous study since then. Residential segregation, as research on race in US cities shows, is detrimental to economic growth, societal equity, and economic mobility leading to alienation of communities (Cutler \& Glaeser 1997). Communities with more diversity have fewer crime rates compared to homogeneous communities (Graif \& Sampson 2009; Letki 2008; Portes \& Vickstrom 2015). A study by Chetty et al. (2014) has shown that the neighborhood 
where one grows up has a major impact on his/her lifetime earnings and success later in life. They find that low residential segregation results in upward social and economic mobility. Since neighborhoods shape the lives of children and youth, children growing in highly segregated poor neighborhoods are more susceptible to failure and emotionally vulnerable (Harding 2003). Neighborhood diversity can have a positive impact on these disadvantaged groups by exposing them to mainstream role models and successful individuals (Wilson 1987). Ludwig et al. (2013) show that moving to a better neighborhood has a positive impact on the physical and mental health of the disadvantageous households. Putnam (2007) argues that the negative effects of diversity are temporary, and that positive consequences of diversity prevail in the long-run.

Segregation also results in ghettoization of minority and poor groups and this aspect of stratification spills over to next generations (Morgan 1984). In times of communal violence, it also becomes easy to target individuals of a particular group or community. Los Angeles riots of 1992, for example, are attributed to highly segregated residential neighborhoods with 'unequal social and political endowments and economic niches' (Morrison, Lowry, \& Rand Corporation 1993). Segregation of residential areas along caste/race lines has resulted in concentration of poverty (for example slums). Residential segregation reproduces and even magnifies the existing social and economic divisions, which can undermine prosperity over time (Carr \& Kutty 2008). Significant increase in socio-educational achievements by Black families which moved to predominantly White neighborhoods is a well-known example (Rubinowitz \& Rosenbaum 2000). Diversity of the neighborhood also ameliorates group anomie. People living in heterogeneous neighborhoods are less discriminative towards people belonging to other races and ethnic groups (Ihlanfeldt \& Scafidi 2002).

In Indian cities, individuals are routinely denied access to housing of their choice based on their caste identity (Thorat et al. 2015). Thomas Schelling(1971) in his seminal paper showed that this simple act of denial or a small preference for one's neighbors to be of the same caste/race could lead to total segregation. Such preferences directly or indirectly give rise to highly segregated neighborhoods and localities based on caste and, often, the distribution of public services and goods are associated with neighborhood characteristics (Miklian \& Sahoo 2016).

\subsection{Caste Based Segregation in Urban India}

The received wisdom is that the sense of relative anonymity provided by urban areas will result in lower levels of caste-based segregation of space. However, the empirical reality of urban India does not live up to this received wisdom - at least not in any whole measure. Historically, Indian cities have usually been segregated along caste lines. According to Karim (1956), the city population in pre-British India was largely segregated geographically by religion, caste and subcaste, and by occupational and regional groups forming social islands. These social units developed such exclusiveness that the groups constituted cities within cities. Gist (1957) in his study of Bengaluru documents caste and religion based residential segregation. Studies of Jatav thoks and mohollas of Agra by Lynch (1967) and of Lucknow rickshawallas by Gould (1965) show caste as an important and even a predominant factor in the organization of urban neighborhoods. Similarly, Hazlehurst (1970) in his study of Puranapur in Haryana finds that while public spaces like markets showed a mixture of castes, residential neighborhoods were highly segregated along caste lines. Mehta (1969) in his study of Pune demonstrates that urbanization, industrialization or modernization had virtually no effect on residential segregation based on caste, religion or ethnicity. In independent India, a wide majority of communal violence incidents is associated with 
urban centres. Hansen (2001) in his study of the rise of Shiv Sena in Mumbai documents how the bonds of caste and religion got transplanted from a village and hardened in an urban setting.

In the early years of the Indian republic, Nehruvian industrial socialism was seen as one of the pathways out of the limitations of narrow parochial identities such as caste, language and religion. The expectation was that over a period of time, caste would cease being a hermetically sealed institution in its urban avatar and would eventually merge into class. But does industrialization, economic growth and urbanization actually dilute the strong communal and kinship bonds of caste? While robust and systematic empirical evidence is scant, anecdotal accounts suggest that the Indian caste system, rather than collapsing to class, has instead adapted to it, preserving its essential features. Economic liberalization in the 1990 s prompted the Indian cities to remodel themselves along post-industrial globalized metropolises. Economic liberalization changed how one looked at Indian cities - at least, at the superficial level it seemed that there might be a structural change in operations of class and caste relations. Caste was supposed to be irrelevant in a globalized setting and influence of traditional caste was apparently being eroded by 'forces of urbanism, secularization, and consumerism' (D’Mello \& Sahay 2008). In a city which is dominated by private sector - where individual agency, knowledge and competence create meritocratic hierarchies, it was argued that caste based ties would become irrelevant. Available empirical evidence suggests that India's embrace of the market economy has not made the expected dent in the operation of caste. For example, Barbara Harriss-White's (2003) work on rural Tamil Nadu demonstrates that India's foray into globalization has not reduced caste based inequalities.

Desai and Dubey (2011) in their nationwide study of caste based inequalities show that early urbanization benefitted privileged upper caste groups. While in metropolitan areas the associated structures of discrimination is somewhat moderated, caste disparities did not structurally disappear with urbanization. The same study demonstrates that caste inequalities are low in developed villages and metropolitan cities compared to smaller cities. Miklian and Sahoo (2016) in their study of three Indian cities note that rather than being "melting pots" and places for upward social mobility, Indian cities stubbornly mirror India's rural social and economic realities and rural social structures are often reproduced in urban settings. They also found out that Muslims and Dalits found it hard to escape the inherent discrimination in a metropolis and thereby pushing them to live in fringes and in segregated neighborhoods.

Using the 2001 census ward-level data on seven largest metro cities of India, Vithayathil \& Singh (2012) show that in the seven largest metro cities of India, 'residential segregation by caste was greater than the degree of residential segregation by socio-economic status.' As we have argued above, given the large size of wards in metro cities, their results are likely to understate the true extent of caste-based segregation. In this paper, we show how a ward is too large to be a considered a neighborhood - especially in the metros where a ward can be as large as a small town. We argue that the real import of caste-based segregation can only be studied at a higher spatial resolution that better approximates a neighbourhood. 


\section{Data and Methodology}

This paper uses data from Census of India 2011 which gives total population (Male and Female) and Scheduled Caste and Tribe population for every enumeration block within a urban ward. ${ }^{2}$ As discussed in the introductory section, a census enumeration block (or sub-block) has around 100-125 households with a population of 650-700. In this paper, we present data for four traditional metropolitan cities of India - Chennai, Delhi, Kolkata and Mumbai along with Bengaluru. Inset tables in Figure 3 list the mean and median ward and block size for these five major urban cities. Clearly, ward sizes vary across cities making them incomparable, but the mean block level size is consistent across all the cities. Figure 3 gives empirical cumulative distribution function (ECDF) plots for block and ward population sizes for all the five cities that we study in this paper. ECDF block population plots of different cities overlap unlike ward plots - denoting comparable block sizes across cities. Table 1 gives total population, and percentage of SC, ST population. For purpose of this paper, we have combined SC and ST population - a standard practice in quantitative studies of urban segregation in India. Since only population numbers are made available at the enumeration block level, we are unable to study segregation based on socioeconomic indicators (class variables), or do a comparative analysis of urban amenities in respective enumeration blocks.

We also use enumeration block maps of Bengaluru (we digitized and geo-registered $\sim 16$,oo polygons representing enumeration blocks and sub-blocks in Bengaluru's 198 wards using official ward maps that we obtained from Census of India and merged block level population data) to present the first visual portrait of the extent of caste-based residential segregation in India. ${ }^{3}$

\begin{tabular}{|l|c|c|c|c|}
\hline \multicolumn{1}{|c|}{ City } & $\begin{array}{c}\text { Total } \\
\text { Population }\end{array}$ & \% SC & \%ST & $\begin{array}{c}\% \\
\text { SC+ST }\end{array}$ \\
\hline Bengaluru & 8443675 & 11.37 & 1.83 & 13.21 \\
\hline Chennai & 4646732 & 16.78 & 0.22 & 17.00 \\
\hline Delhi & 11034555 & 15.76 & 0.00 & 15.76 \\
\hline Kolkata & 4496694 & 5.38 & 0.24 & 5.62 \\
\hline Mumbai & 12442373 & 6.46 & 1.04 & 7.50 \\
\hline
\end{tabular}

Table 1: City population and percentage of SCs and STs (Data from Census of India, 2011). Census numbers underestimate the number of people belonging to SC and ST groups. This is best illustrated by Delhi where census numbers report no person belonging to the ST group - which evidently does not reflect empirical reality. This discrepancy arises from the fact that Census uses state-specific SC and ST lists to tabulate group populations. Delhi does not have a state-specific ST list. People who belong to ST groups under lists from other states are not enumerated as ST in Delhi. Similar process is followed for enumeration of people belonging to SC groups as well. Thus, for example, only people belonging to groups that are in the Karnataka SC list are counted under SC for the city of Bengaluru. A person belonging to an SC group that is recognized as such outside Karnataka is not enumerated as an SC in Bengaluru. 

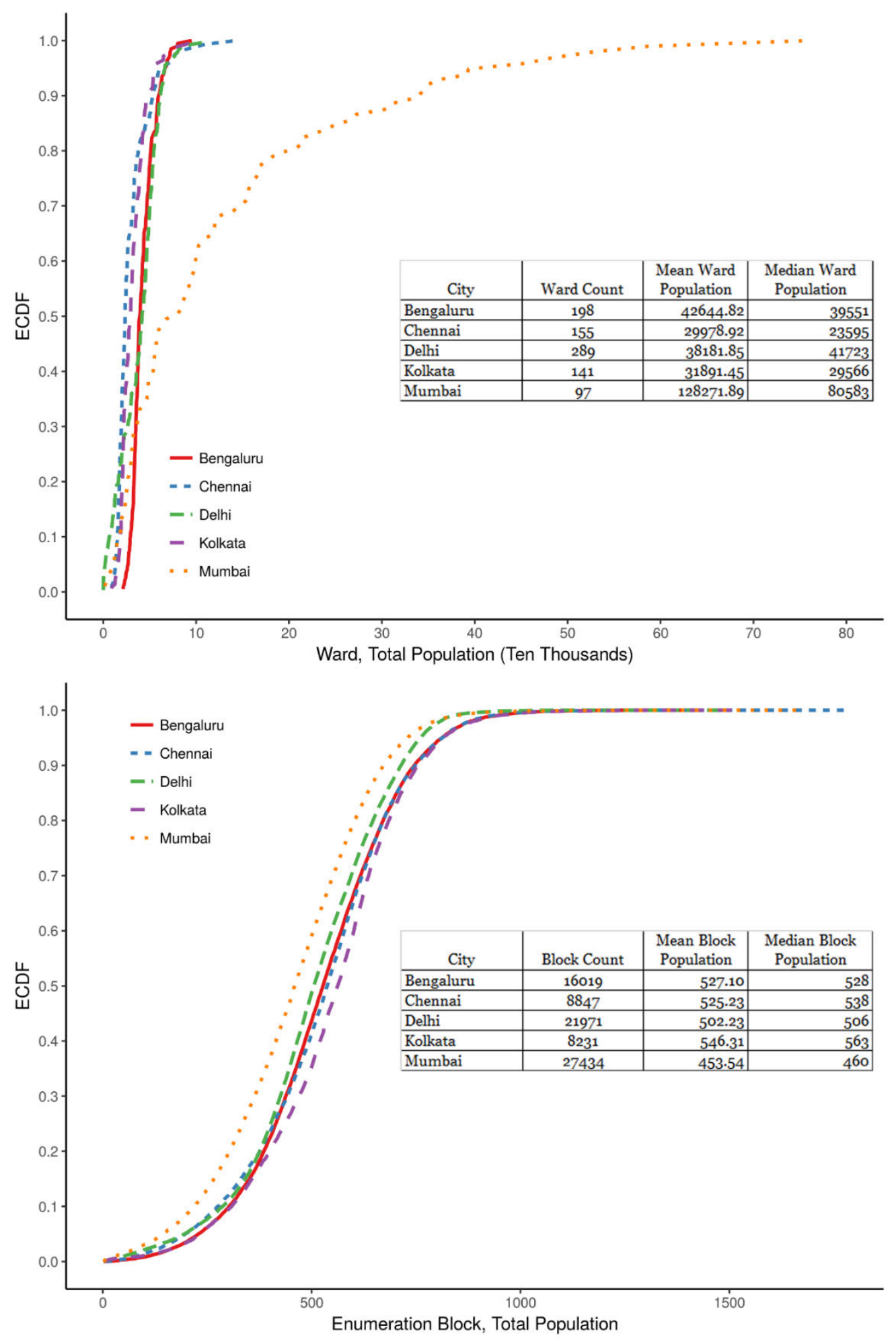

Figure 3: Cumulative density plots of population at ward and block levels. Data from Census 2011. These plots provide the basis (or lack thereof) for comparisons across the five metro cities in India. The top panel shows the density plot at the ward level. Ward sizes are comparable across cities except Mumbai that has much larger wards. The block sizes (bottom panel) are comparable across all cities. 


\subsection{Measuring Segregation}

We use a simple dissimilarity index and the standard Gini index to measure residential segregation. Both indices measure degree of 'evenness' of a given geographical unit. The dissimilarity index measures how population shares of different social groups are different from the larger spatial aggregate. In our case, we ask how blocks in the ward are different from the ward itself. We also study how blocks are different from the city as a whole. To benchmark our blocklevel results with earlier ward-level results, and illustrate the extent of intra-ward segregation, we also present results for how wards in the city are different from city as a whole. Both the indices vary from 0 to 1 , with 0 indicating complete integration; and 1, complete segregation.

We compute a simple Dissimilarity Index (D) at city and ward levels. We compute two different dissimilarity indices at the city-level, and one at the ward-level. At the city-level, we ask how the caste composition of a ward or a block is different from the city as a whole. To understand intra-ward heterogeneity, we also compute the dissimilarity index at the ward level - an indicator of how the blocks within a ward are different from ward as a whole. We use a simple index defined by:

$$
D=0.5 \sum_{i=1}^{N}\left|\frac{S_{i}}{\mathbf{S}}-\frac{r_{i}}{\mathbf{R}}\right|
$$

where $S_{i}=\mathrm{SC}+\mathrm{ST}$ population in $\mathrm{i}^{\text {th }}$ block/ward

$\mathbf{S}=$ Total SC+ST population in ward/ city

$r_{i}=$ Rest of the population $\mathrm{r}^{\text {th }}$ block/ward

$\mathbf{R}=$ Rest of the population in ward/ city

We also compute a simple Gini index as an index of segregation for each of the five cities that we study.

Gini index (G) of a city is calculated using:

$$
G=\frac{\sum_{i=1}^{n} \sum_{j=1}^{n}\left|s_{i}-s_{j}\right|}{2 n \sum_{i=1}^{n} s_{i}}
$$

where $S_{i}$ and $S_{j}$ are SC-ST populations in ward (or block) $i$ and $j$ respectively. 


\section{Results}

Table 2 presents the three different dissimilarity indices that we compute in the paper. The first column reports the dissimilarity index computed at the ward-city level, and represents the benchmark result - for example, these numbers are consistent with numbers reported by Vithayathil \& Singh (2012). As discussed, this index is a measure of how wards within a city are different in their caste composition from the city as a whole. The second column reports the dissimilarity index comptued at the block-city level - a measure of how the caste composition of blocks in a city are different from city as a whole. A comparison between these two columns illustrates how ignoring intra-ward segregation amounts to neglect of a significant portion of segregation in a city. The last two columns present a direct measure of intra-ward segregation. For each ward, we computed how the blocks within the ward are different from the ward as a whole in terms of caste composition. The table reports the median ward-block dissimilarity index for each city as well as a mean (ward population weighted). As seen from the table, for a typical ward, the dissimilarity index computed at ward-block level is greater than the one computed at ward-city level - and thus showing how wards are heterogenous and segregated.

In Figure 4, each of the six panels (corresponding to the five individual cities studied in this paper, and one corresponding to combinded data from all the five cities) show two different SC-ST population Lorenz curves - one computed at the ward-level, and other computed at the block-level. For each of the five cities, the ward-level Lorenz curve lies unambiguously, and wholly inside the block-level Lorenz curve. The degree of intra-ward heterogeneity is seen from the difference in Gini coefficients at block and ward levels. The Gini coefficients reported here are a measure of segregation at ward and block levels. This figure clearly illustrates why treating ward as a homogenous entity is empirically fraught. For example, in Bengaluru, there is a $30 \%$ difference between segregation measured at block and ward levels as mesaured by the Gini index.

Figure 5 illustrates how there is no systematic relationship between ward size and the dissimilarity index. The first panel in the figure combines wards from all five cities that we study in this paper. This figure provides evidence for intra-ward heterogeneity across ward sizes. Figure 6 illustrates the extent of intra-ward heterogeneity. For each of the five cities, as well as for the combined dataset, we present the distribution of the block-ward dissimilarity index.

Figure 7 juxtaposes kernel density plots for fractionalization index computed at block and ward levels for each of the five cities (the first panel combines blocks and wards from all five cities). Even when wards are diverse (higher fractionalization), the blocks are homogenous (lower fractionalization). The fractionalization index is usefully interpreted as the probability that two randomly selected people (here, from either a ward or a block) belong to different social groups (here either SC-ST or OTH). 


\begin{tabular}{|l|r|r|r|r|}
\hline \multicolumn{1}{|c|}{ City } & $\begin{array}{c}\text { D } \\
\text { (Ward-City) }\end{array}$ & \multicolumn{1}{c|}{$\begin{array}{c}\text { D (Block- } \\
\text { City) }\end{array}$} & $\begin{array}{c}\text { Median D } \\
\text { (Block-Ward) }\end{array}$ & $\begin{array}{l}\text { Pop. W (Block-Ward) } \\
\text { D Mean }\end{array}$ \\
\hline Bengaluru & 0.23 & 0.51 & 0.46 & 0.46 \\
\hline Chennai & 0.33 & 0.62 & 0.56 & 0.53 \\
\hline Delhi & 0.33 & 0.60 & 0.54 & 0.54 \\
\hline Kolkata & 0.37 & 0.71 & 0.67 & 0.67 \\
\hline Mumbai & 0.21 & 0.59 & 0.59 & 0.57 \\
\hline
\end{tabular}

Table 2: Patterns of Segregation: Dissimilarity Index. See main text for computational details.
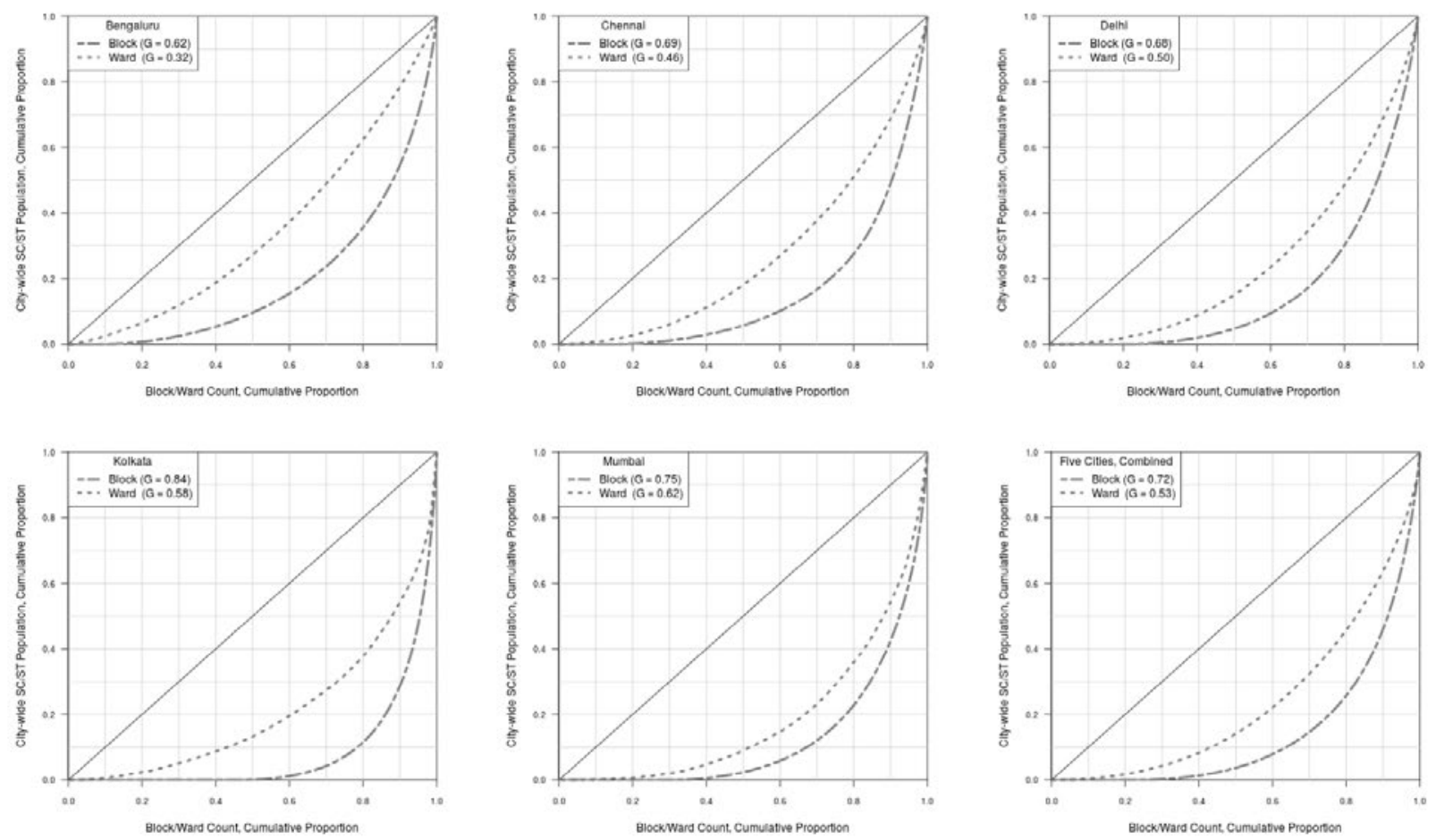

Figure 4: Block and Ward Segregation: Lorenz curves. 

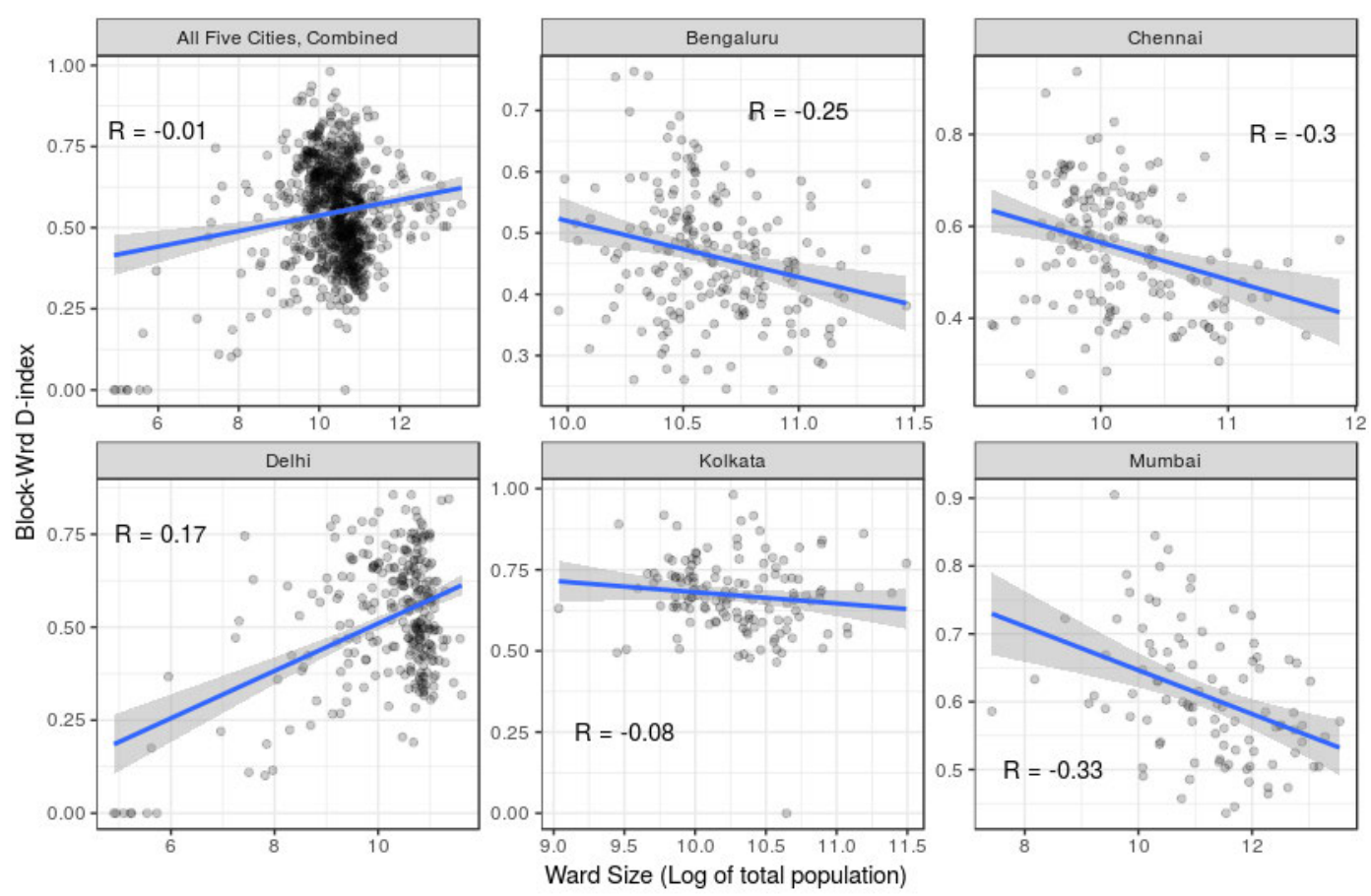

Figure 5: Relationship between ward-size and block-ward dissimilarity index.
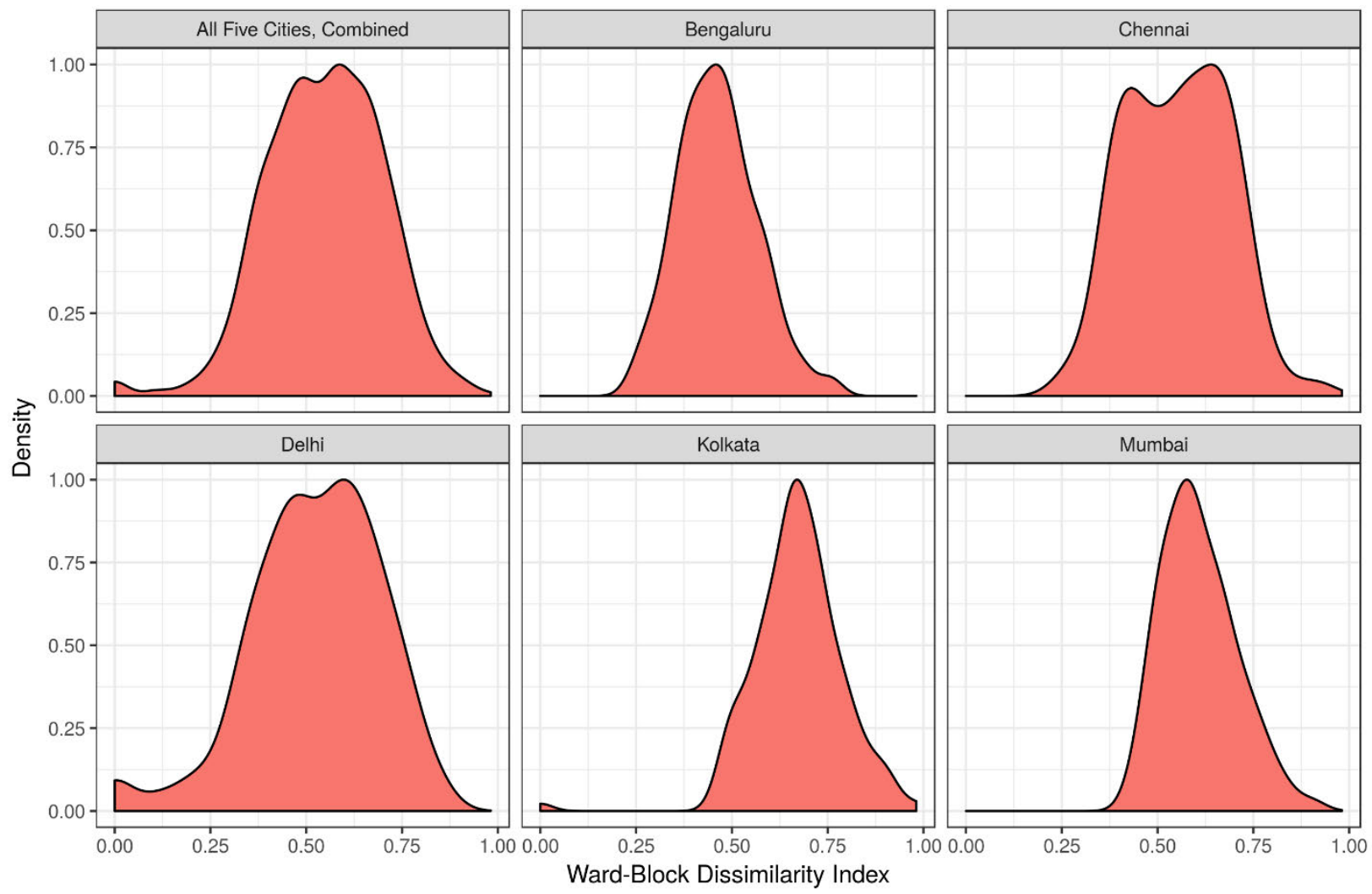

Figure 6: Kernal density plots of ward-block dissimilartiy index 


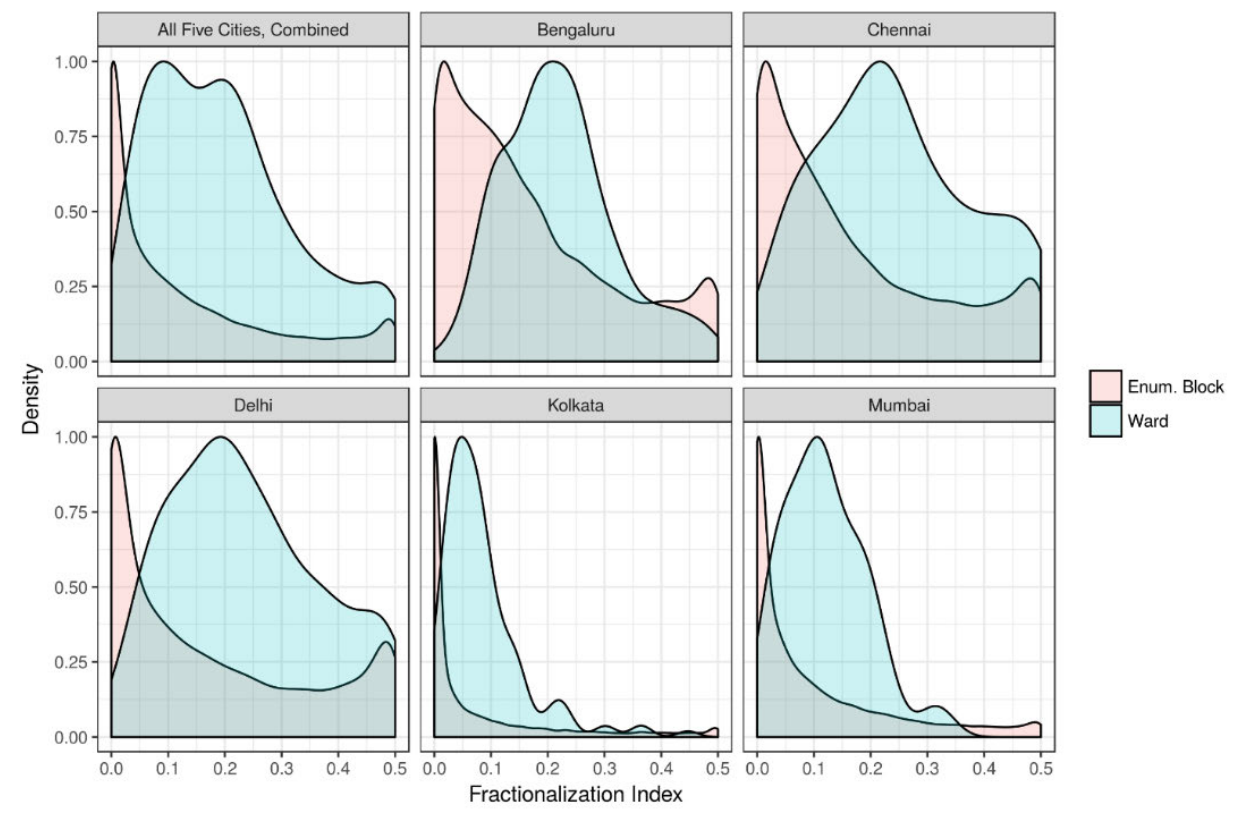

Figure 7 Ward diversity and Block Homegeneity

\section{Visualizing Quantitative Segregation Results: The Case of Bengaluru}

We illustrate the quantitative results from the section spatially using Bengaluru as our case study. Considered as the IT hub of India, Bengaluru (also known as Bangalore) is a great example of changes which economic liberalisation can bring about in the form and fabric of a city. In 2011 the number of foreign investment projects in the city was eighth highest in the world (Fingar, 2013). Bengaluru was founded in the 1537 by Kempegowda, a local chieftain. At the time of Kempegowda, the city was divided into several petes - each one for different trades and profession - which was similar to any other traditional Indian city. Nagarthpete was for textile and gold traders, Ganigarapete was for Ganigas - the oil pressing caste, Cubbonpete- was for people of the Devanga community who were the weavers of traditional silk sarees, Kumbarapete for potters, Upparapete was for the members of the Uppara caste, Thigalarapete was for Thigalas and so on (Nair, 2005). After the British captured the city in 1791, the documents show that the city was divided and organised along caste lines (Buchanan 1807).

When the British settled in Bengaluru, they chose not to have any connections with the existing city and started a new military settlement - Cantonment in 1809 far from the existing settlement. The population of the Cantonment mainly consisted of Europeans and Tamil speakers who were part of the Madras regiment. It took more than a century for these two different cities to merge. Even today, the difference between these two parts of the city is quite felt in terms of culture, language and landscape.

During World War II and after independence various public-sector industries were started in Bengaluru that resulted in migration from other parts of India. Noel Gist (1958) in his study of Bengaluru notes that there were some neighbourhoods in the city where a large number of families belonging to depressed classes (Scheduled Castes) lived. He also notes that areas of highest occupancy by depressed castes were on or near the city's outskirts. Members of Brahmin caste showed similar tendencies of segregated residence. Brahmins were concentrated in the 
western part of the city. The areas occupied heavily by Brahmins and other high caste Hindus were attractive residential districts, among the most sought after as the city grew. Muslims were highly segregated and lived in highly congested neighbourhoods. Majority of the Christians lived in Cantonment, and among them Anglo-Indians lived separately. (Gist, 1957) concludes that spatial isolation of various communities reflected their social isolation, too.

Economic liberalisation brought about profound changes in the economy of the city. During the 1990s, Bengaluru was a preferred location for many Information technology (IT) related industries and Bengaluru emerged as a globally integrated centre of high-technology research and production (Dittrich 2007). This boom in economy created enormous employment opportunities and allied service sector grew at a faster pace. As a result, Bengaluru became one of the fastest growing cities in India in terms of population and geographical area. Bengaluru urban district's population grew at a whopping rate of 46.68 per cent over the past decade (2001-2011) as compared to 7.65 per cent growth of Chennai and 4.2 per cent growth rate of Mumbai (Bose 2013). This has changed the demography and geography of the city. The socio-cultural dynamics and the urban settlement patterns have had a momentous change (Dittrich 2007).

We use EB level maps of Census 2011 to study the intra-ward level residential segregation in Bengaluru. Figure 8 illustrates the spatial variation of SC-ST population in Bengaluru. As we can notice, there are many neighborhoods (EBs) with no SC-ST population and neighborhoods with substantial SC-ST population denoting high segregation. Figure 9 zooms in on a particular portion of Figure- 8 to better illustrate intra-ward variation in $\mathrm{SC}+\mathrm{ST}$ populations. 


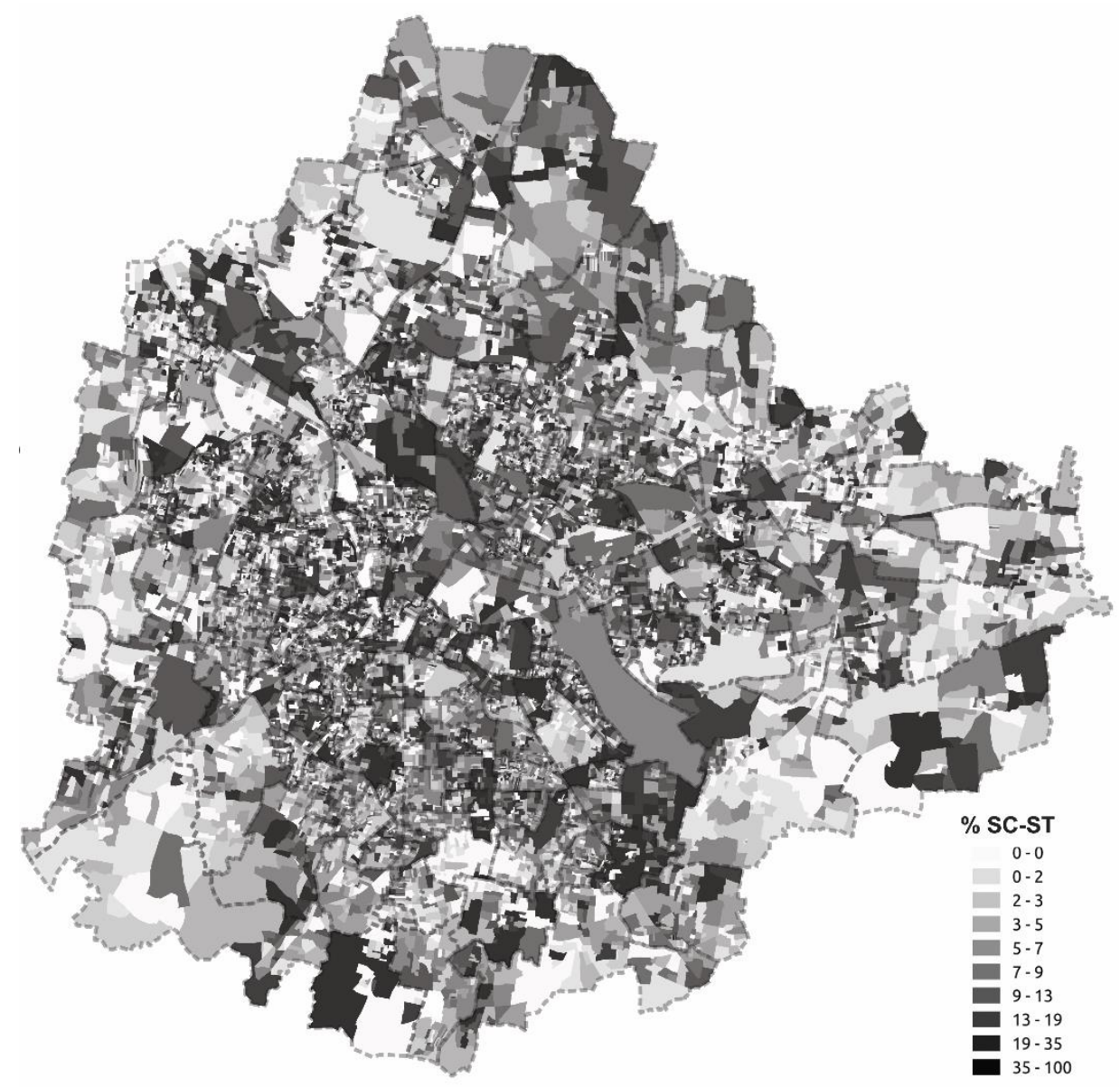

Figure 8 Bengaluru enumeration block level SC+ST population variation. The population numbers, ward boundaries, and block boundaries are all from Census of India (2011). Ward boundaries in dotted. Also cf. Figure-11

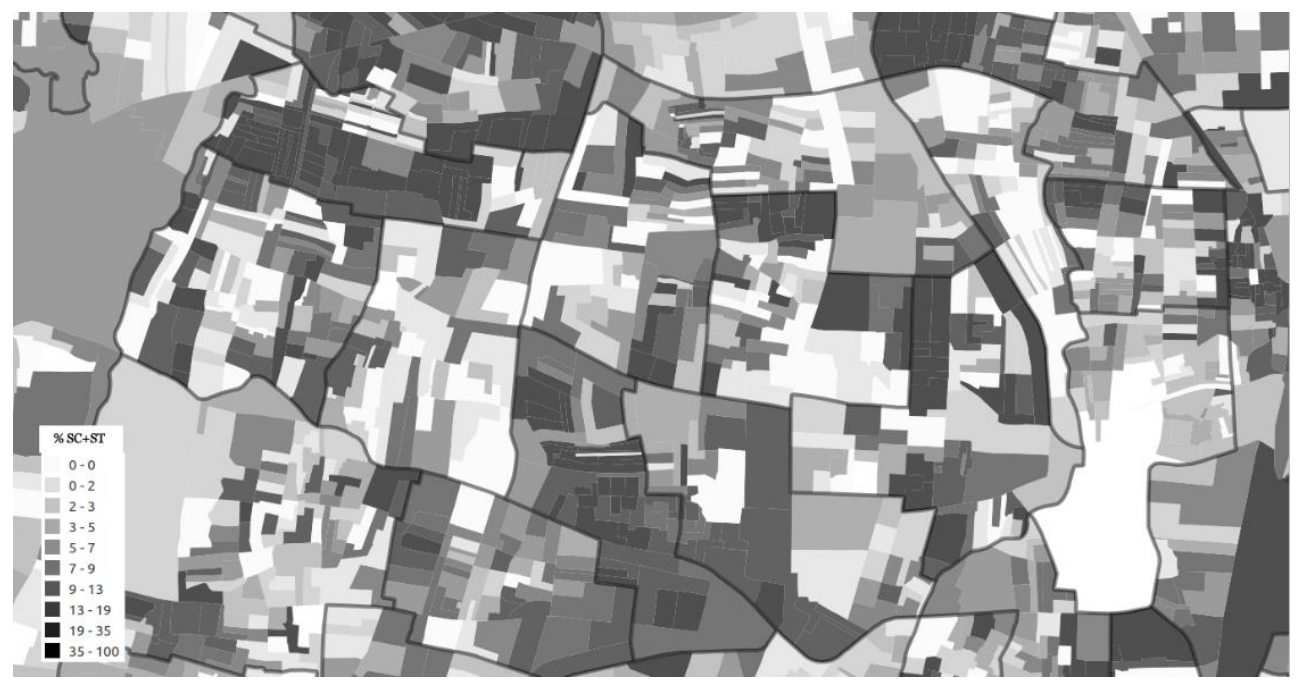

Figure 9: Variation of $S C+S T$ population within wards in Bengaluru. This figure zooms in on a particular portion of Figure-10 to better illustrate intra-ward variation in $S C+S T$ populations. As we can notice, within a ward, there can be blocks with no SC+ST population and blocks with substantial SC+ST population. This illustrates how neighborhoods within ward are highly segregated and studies on segregation at ward level amounts to neglect of a significant portion of segregation in a city. 


\section{Conclusion}

We presented the first ever neighbourhood-scale segregation patterns in India's major urban centres, and in the case of Bengaluru, the first visual map of neighbourhood-scale segregation of space by caste. Our analysis provides the first ever systematic neighborhood-scale evidence for urban segregation in India - in a discourse dominated by anecdotal accounts of ethnic space making in urban India. Our analysis immediately point to severe data limitations that has constrained scholarship, policy, and praxis surrounding urbanization. The results of this paper make a strong case for future census data to be released at a geo-tagged enumeration block resolution. The project team collectively spent over 90 fulltime person days to digitize and georeference block level data - effectively replicating digital data that the Census of India does not make public. If an analog version is made public, there is no reason why a digital version should not also be made public. Currently, the Census of India releases enumeration block level data for only basic population numbers that does not permit characterizing segregation based on other socio-economic axes or characterize the uneven availability of public goods in different neighbourhoods. By developing a visual portrait of segregation for Bengaluru, this paper has demonstrated that enumeration block data must become the bedrock for any policy and praxis focused on building inclusive urban spaces.

While our analysis provides the most detailed portrait to date of spatial segregation in urban India, our snapshot provides little insights into the causal pathways that can explain the linkages between urbanization and ethnic space making. A significant limitation of the portrait we have presented here is that we have not been able to control for non-ethnic characteristics of the neighborhoods. For example, we do not know if the pattern of social segregation of space that we have presented here holds across economic classes since enumeration block level data on neighborhood amenities such as education is not available in public domain. Data limitations also prevent us from studying residential segregation along religious lines.

Data limitations notwithstanding, our results pose a significant challenge to one of the bedrock normative promises of urbanization in India - the dilution of caste boundaries Indian cities (at least the cities presented in the paper, and there is no reason to believe the results will be very different in other urban centres) remain highly segregated along caste lines. Thus, studying patterns of urban segregation offers an important window to understanding the robust perseverance of caste structures in contemporary India.

\footnotetext{
${ }^{1}$ Census of India Abstract, 2011. For an excellent summary of earlier periods, see (Teltumbde, 2016)

2 Appendix 1, Table A-12 of the Census Abstract, 2011.

3 The Census of India does not make available digital files for census enumeration blocks. $C f$. concluding section of this paper for our arguments about why future census operations must make geo-coded enumeration block data available in digital format.
}

\section{References}

Béteille, A. (1965): Caste, class, and power: changing patterns of stratification in a Tanjore village. Berkeley: University of California Press.

Beteille, A. (1997): India's middle-class. Internationale Politik, 52(3), 17-20. 
Borooah, V. (2010): Inequality in health outcomes in India: the role of caste and religion. Bose, P. (2013): Population boom: At 46.68\%, Bangalore tops urban districts. Business Standard. Retrieved on 6/4/18 from https://www.businessstandard.com/article/economy-policy/population-boom-at-46-68-bangalore-topsurban-districts-111040700056_1.html

Burgess, E. W. (1928): Residential segregation in American cities. Annals of the American Academy of Political and Social Science, 140, 105-115.

Carr, J. H., \& Kutty, N. K. (2008): Segregation: The rising costs for America. Routledge.

Chaskin, R. J. (1994): Defining neighborhood. Chapin Hall Center for Children at the University of Chicago.

Chetty, R., Hendren, N., Kline, P., \& Saez, E. (2014): Where is the land of opportunity? The geography of intergenerational mobility in the United States. National Bureau of Economic Research.

Cutler, D. M., \& Glaeser, E. L. (1997): Are ghettos good or bad? Quarterly Journal of Economics, 112, 827-872.

Desai, A. R. (1994): Rural sociology in India. Popular Prakashan.

Desai, S., \& Dubey, A. (2011): Caste in the 21st Century India. Competing Narratives, EPW, $46(11)$.

Deshpande, A. (2000): Does Caste Still Define Disparity? A Look at Inequality in Kerala, India. The American Economic Review, 9o(2), 322-325.

Deshpande, A. (2001): Caste at Birth? Redefining Disparity in India. Review of Development Economics, 5(1).

Dittrich, C. (2007): Bangalore: globalisation and fragmentation in India's hightech-capital. Asien, 103(3), 45-58. 
D’Mello, M., \& Sahay, S. (2008): Betwixt and between? Exploring mobilities in a global workplace in India. In an Outpost of the Global Economy. Work and Workers in India's Information Technology Industry, 76-100.

Dupont, V. (2004): Socio-spatial differentiation and residential segregation in Delhi: a question of scale? Geoforum, 35(2), 157-175.

Fingar, C. (Ed.). (2013): The fDi Report. Global Greenfield Investment Trend. London: The Financial Times Ltd.

Gayer, L., \& Jaffrelot, C. (2012): Muslims in Indian Cities: Trajectories of Marginalisation. Columbia University Press.

Ghurye, G. S. (1969): Caste and race in India. Bombay: Popular Prakashan.

Gist, N. P. (1957): The ecology of Bangalore, India: an east-west comparison. Social Forces, $356-365$.

Gist, N. P., \& Fava, S. F. (1970): Urban society. Thomas Y. Crowell.

Gould, H. A. (1965): Lucknow rickshawallas: the social organization of an occupational category. International Journal of Comparative Sociology, 6, 24.

Graif, C., \& Sampson, R. J. (2009): Spatial heterogeneity in the effects of immigration and diversity on neighborhood homicide rates. Homicide Studies.

Hansen, T. B. (2001): Wages of violence: naming and identity in postcolonial Bombay. Princeton University Press.

Harding, J. D. (2003): Counterfactual models of neighborhood effects: The effect of neighborhood poverty on dropping out and teenage pregnancy. American Journal of Sociology, 109, 676-719.

Harriss-White, B. (2003): India working: Essays on society and economy (Vol. 8). Cambridge University Press.

Hazlehurst, L. W. (1970): Urban space and activities. Urban India: Society, Space and Image. Richard G. Fox Ed, 186-195. 
Iceland, J., \& Weinberg, D. H. (2002): Racial and ethnic residential segregation in the United States 1980-200o. Bureau of Census.

Ihlanfeldt, K. R., \& Scafidi, B. (2002): Black self-segregation as a cause of housing segregation: Evidence from the multi-city study of urban inequality. Journal of Urban Economics, 51(2), 366-390.

Karim, A. K. N. (1956): Changing society in India and Pakistan: a study in social change and social stratification. Oxford University Press.

Kothari, R. (1995): Caste in Indian politics. Orient Blackswan.

Lee, B. A., \& Campbell, K. E. (1997): Common ground? Urban neighborhoods as survey respondents see them. Social Science Quarterly, 922-936.

Letki, N. (2008): Does diversity erode social cohesion? Social capital and race in British neighbourhoods. Political Studies, 56(1), 99-126.

Logan, J. R., \& Collver, O. A. (1983): Residents' perceptions of suburban community differences. American Sociological Review, 428-433.

Ludwig, J., Duncan, G. J., Gennetian, L. A., Katz, L. F., Kessler, R. C., Kling, J. R., \& Sanbonmatsu, L. (2013): Long-term neighborhood effects on low-income families: Evidence from Moving to Opportunity. National Bureau of Economic Research.

Lynch, O. M. (1967): Rural cities in India: continuities and discontinuities. India and Ceylon: Unity and Diversity, 142-158.

Massey, D. S., \& Denton, N. A. (1987): Trends in the residential segregation of Blacks, Hispanics, and Asians: 1970-1980. American Sociological Review, 802-825.

Mehta, S. K. (1969): Patterns of residence in Poona, India, by caste and religion: 1822-1965. Demography, 6(4), 473-491.

Miklian, J., \& Sahoo, N. (2016): Supporting a More Inclusive and Responsive Urban India. Available at SSRN. 
Morgan, B. S. B. (1984): Social geography, spatial structure and social structure. GeoJournal, 9(3), 301-310.

Morrison, P. A., Lowry, I. S., \& Rand Corporation. (1993):A riot of color: the demographic setting of civil disturbance in Los Angeles.

Mukherjee, R. (1968): The Way of Humanism. Academic Books

Nair, J. (2005): The promise of the metropolis: Bangalore's twentieth century. Oxford University Press, USA.

Nambissan, G. B. (2009): Exclusion and discrimination in schools: Experiences of dalit children. Indian Institute of Dalit Studies and UNICEF.

Park, R. E., Burgess, E. W., McKenzie, R. D., \& Wirth, L. (1925): The city: Suggestions for investigation of human behavior in the urban environment. Chicago: Univ. of Chicago Press.

Portes, A., \& Vickstrom, E. (2015): Diversity, social capital, and cohesion. Migration: Economic Change, Social Challenge, 161.

Prasad, C. B. (2010): New Order. Himal South Asian.

Prasad, R. N. (2006): Urban local self-government in India. Mittal Publications.

Putnam, R. D. (2007): Bowling alone: the collapse and revival of American community. Simon \& Schuster.

Rao, A. (2009): The Caste Question Dalits and the Politics of Modern India. Berkeley: University of California Press.

Rubinowitz, L. S., \& Rosenbaum, J. E. (2000): Crossing the class and color lines: From public housing to white suburbia. University of Chicago Press.

Schelling, T. C. (1971): Dynamic models of segregation†. Journal of Mathematical Sociology, 1(2), 143-186.

Shaw, A. (2012). Indian cities: New Delhi: Oxford University Press. 
Sidhwani, P. (2015): Spatial inequalities in big Indian cities. Economic \& Political Weekly, $50(22), 55$.

Socio-Economic and Caste Census. (2011): Supervisor's Manual. Ministry of Rural Development \& Ministry of Housing and Urban Poverty Alleviation. Retrieved on 6/4/18 from http://rural.nic.in/sites/default/files/Supervisory\%20Manual\%2020\%20June\%202012 \%20\%28English\%29_1.pdf

Swallow, D. A. (1982): Ashes and Powers: Myth, Rite and Miracle in an Indian God-Man's Cult. Modern Asian Studies, 16(01), 123-158.

Teltumbde, A. (2016): Dalits: Past, Present and Future. Taylor \& Francis.

Thorat, S., Banerjee, A., Mishra, V. K., \& Rizvi, F. (2015): Urban Rental Housing Market. Economic \& Political Weekly, 27, 47-53.

Thorat, S., \& Neuman, K. S. (2012): Blocked by caste: economic discrimination in modern India. Oxford University Press.

Vithayathil, T., \& Singh, G. (2012): Spaces of Discrimination. Economic \& Political Weekly, 47(37), 6o-66.

Wilson, W. J. (1987): The Truely Disadvantaged. The Inner City the Underclass and Public Policy, The University of Chicago Pres, Chicago. 